\title{
ELECTROCARDIOGRAMS WITH SHORT P-R INTERVAL AND ABERRANT QRS COMPLEX
}

\author{
BY \\ L. M. SANGHVI AND S. N. MISRA \\ From the Department of Cardiology, Sawai Man Singh Hospital and Medical College, Jaipur, India \\ Received September 7, 1957
}

Electrocardiograms with short P-R intervals and aberrant QRS complexes (WPW beats), characteristic of the classical congenital Wolff-Parkinson-White syndrome, have been reported in hypertension, in arteriosclerotic and rheumatic heart disease, during cardiac catheterization and pneumonectomy, and after administration of digitalis and strophanthin. Borduas et al. (1955) noted the frequent clinical occurrence of beats with a short P-R interval and normal or abnormal QRS which were obviously not of the classical type. Hoffman et al. (1956) reported five instances of WPW aberration in patients with arteriosclerotic heart disease seen during a two-year period at three active hospitals, only one being an example of the classical type. Four cases with the acquired type of WPW beats associated with certain uncommon features in the electrocardiogram are here reported.

\section{CASE REPORTS}

Case 1. A 30-year-old man was admitted because of cough, exertional dyspnœa, palpitation, and præcordial ache of fifteen days' duration. He had had attacks of joint pains at intervals for five years. On examination, he had rheumatic aortic regurgitation and early congestive failure. The heart was moderately enlarged with left ventricular configuration on fluoroscopy. The blood pressure was $110 / 55$.

The electrocardiogram (Fig. 1) showed a pattern of left ventricular strain with inverted $\mathrm{T}$ waves in leads I, aVL, and V4-6. The sinus rate varied between 115 and 125 a minute (R-R $0.48-0.52)$ and

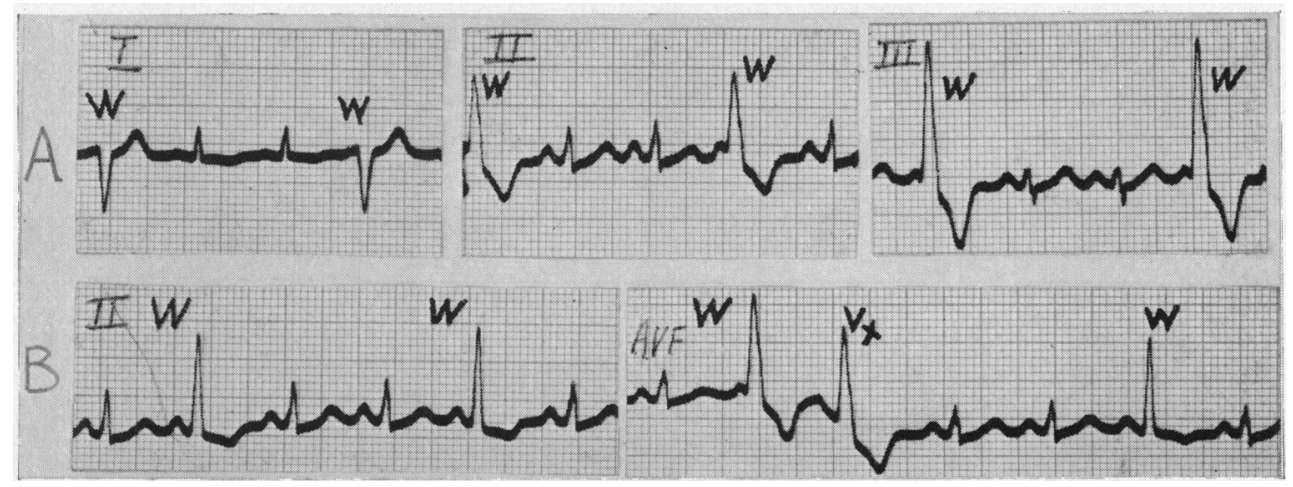

FIG. 1.-Case 1. Electrocardiogram, showing WPW complexes produced by parasystolic rhythm.

in the sinus beats the P-R interval was 0.16 and the QRS duration 0.07 sec. In record $A$ aberrant complexes with short $\mathrm{P}-\mathrm{R}$ interval (W) occur after every two sinus beats at intervals of $1.46-1.50 \mathrm{sec}$. (i.e. $3 \times 0 \cdot 50=1 \cdot 50$ ) giving rise to a trigeminal rhythm. In record $B$, obtained soon after $A$, the $R-R$ 
interval between successive WPW beats was either $1.50 \mathrm{sec}$. (lead II) or $2 \cdot 10 \mathrm{sec}$ (aVF). In these leads there are WPW beats with a QRS duration not exceeding that in sinus beats $(0.07 \mathrm{sec}$.), and a $P-R$ interval of $0 \cdot 14$ sec. There is a premature complex in aVF $\left(V_{x}\right)$ similar in contour to the QRS of the preceding WPW beat. A similar complex is seen in aVL. Numerous premature complexes from another focus were seen in lead I (not shown in figure). In the WPW beats in this case, the P-R interval varied from 0.07 to 0.14 sec., QRS duration from 0.07 to 0.10 sec., and the P-S duration from $0 \cdot 18$ to 0.21 sec. The QRS contour also varied greatly.

Case 2. A 57-year-old man was admitted unconscious with a history of cough and dyspnœa for three months, and aphasia and hemiplegia of the right side for two months. Oedema of the feet and ascites had developed 15 days before and he had been unconscious for seven days. On examination, he had Cheyne-Stokes respiration, generalized anasarca and ascites, grossly enlarged liver, and irregular heart rhythm with a rate of about 100 a minute; the blood pressure was 130/100, and hemiplegia of the right side was present. At the apex the heart sounds were faint and there was a protodiastolic gallop; the aortic and pulmonary second sounds were accentuated. Laboratory examination showed normal urine and cerebrospinal fluid, negative Kahn test, and blood urea $35 \mathrm{mg}$. per $100 \mathrm{ml}$. Clinically the diagnosis was myocardial infarction followed later by cerebral embolism and congestive failure. The patient died on the eighth day after admission. Autopsy could not be obtained.

The electrocardiogram (Fig. 2) revealed a pattern of left ventricular strain with inverted T waves in leads I, aVL, and V5-6 and QS deflections in V1-3 suggestive of old anteroseptal infarction. The

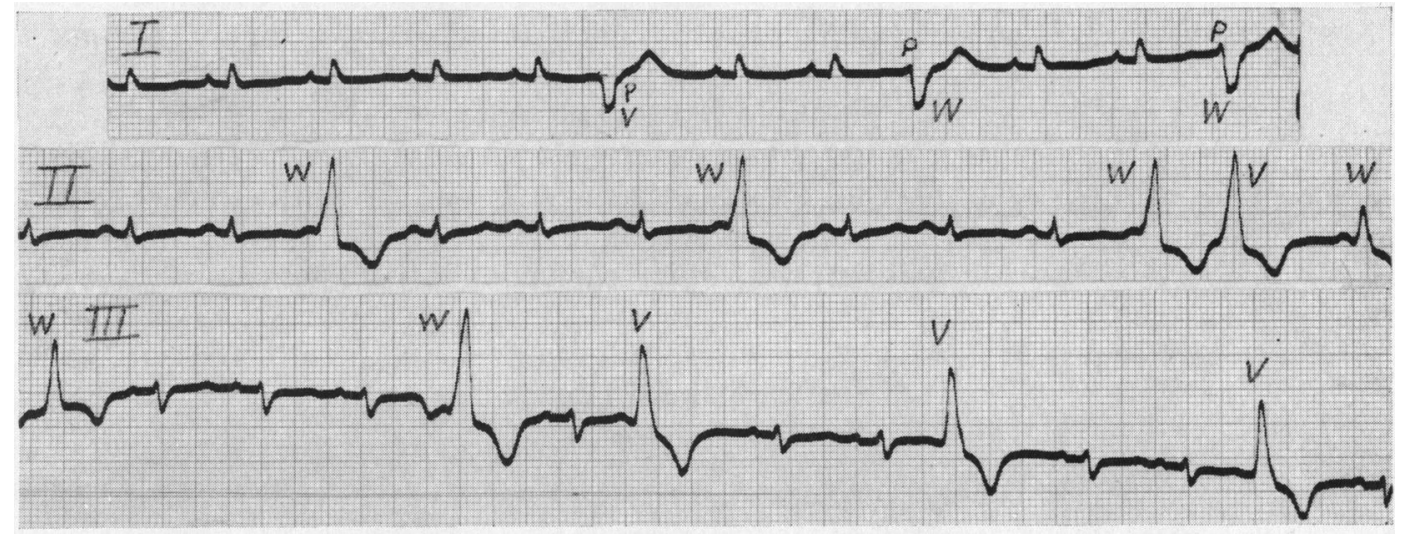

FiG. 2.-Case 2. Electrocardiogram, showing WPW complexes produced by parasystolic rhythm with fusion beats.

sinus rate was 97 a minute and in the sinus beats the P-R interval was $0 \cdot 18$ and QRS duration $0 \cdot 10$ sec. Lead I shows a premature complex and two WPW beats with similar QRS contour and duration of $0.14 \mathrm{sec}$, at intervals of $1.88 \mathrm{sec}$. The latter two closely follow a $P$ wave after a $P-R$ interval of 0.04 and 0.06 sec., respectively. In leads II and III WPW/beats occur at intervals of $2.48 \mathrm{sec} .(2 \times 1.24)$ except the last beat in lead II which occurs after 1.24 sec. In lead III there are also premature complexes at intervals of $1.88 \mathrm{sec}$. Other leads showed WPW beats or premature complexes at regular intervals. The $P-R$ interval was $0 \cdot 14$ and the $Q R S$ duration $0 \cdot 10$ sec. in the last WPW beat in lead II, while they were $0 \cdot 13$ and $0 \cdot 11 \mathrm{sec}$. respectively in the first WPW beat in lead III. In the WPW beats in this case the P-R interval varied from $0 \cdot 04$ to $0 \cdot 14$, QRS duration from $0 \cdot 10$ to $0 \cdot 14$, and $\mathrm{P}-\mathrm{S}$ duration from $0 \cdot 18$ to $0 \cdot 24 \mathrm{sec}$. Long strips showed WPW beats with variable coupling at intervals of 1.24 or 2.48 or $3.80(3 \times 1.24)$ sec. and premature complexes at intervals of $1.88 \mathrm{sec}$.

Comment. In the above two cases there were premature complexes with a short $\mathrm{P}-\mathrm{R}$ interval (WPW) and others without a preceding P wave. Diagnosis of genuine WPW beats of the classical 
syndrome is usually made when (i) the aberrant QRS has an initial slow rising slurred delta wave; (ii) the short P-R interval of these beats does not change regardless of the cycle length; and (iii) such beats occur in at least two successive cycles (Katz and Pick, 1956). In these cases, though a delta wave was present in some of the beats, the latter two criteria were absent. Again the wide variation of the P-R interval and of QRS duration and contour in most of these beats, and the presence of other premature complexes in the same record left little doubt that the beats were ventricular fusion complexes (except in Case 2, lead 1) resulting from interference between ectopic impulse and a sinus impulse in the ventricles. That this ectopic impulse originated in a parasystolic centre was demonstrated by (i) the R-R intervals between successive WPW beats being multiples of a common denominator and (ii) the variation of the coupling of these beats, the QRS complexes occurring at different times in the cardiac cycle.

In Case 2 a second parasystolic centre caused aberrant complexes at regular intervals. In some of these (lead I) the QRS closely follows a P wave at an interval of less than 0.07 sec. which is considered to be the minimum conduction time from the S-A node to A-V node, and its duration and contour is similar to the premature complex without a $\mathbf{P}$ wave. These WPW beats, therefore, though preceded by a $\mathbf{P}$ wave, are pure ectopic complexes occurring very prematurely and not fusion beats. Occurrence of premature complexes similar to the fusion complex in Case 1 is difficult to explain.

Case 3. A 52-year-old man had acute infarction of the diaphragmatic surface of the heart in June 1955. A routine cardiogram (Fig. 3) showed $Q$ waves and inverted $T$ waves in leads II, III, and

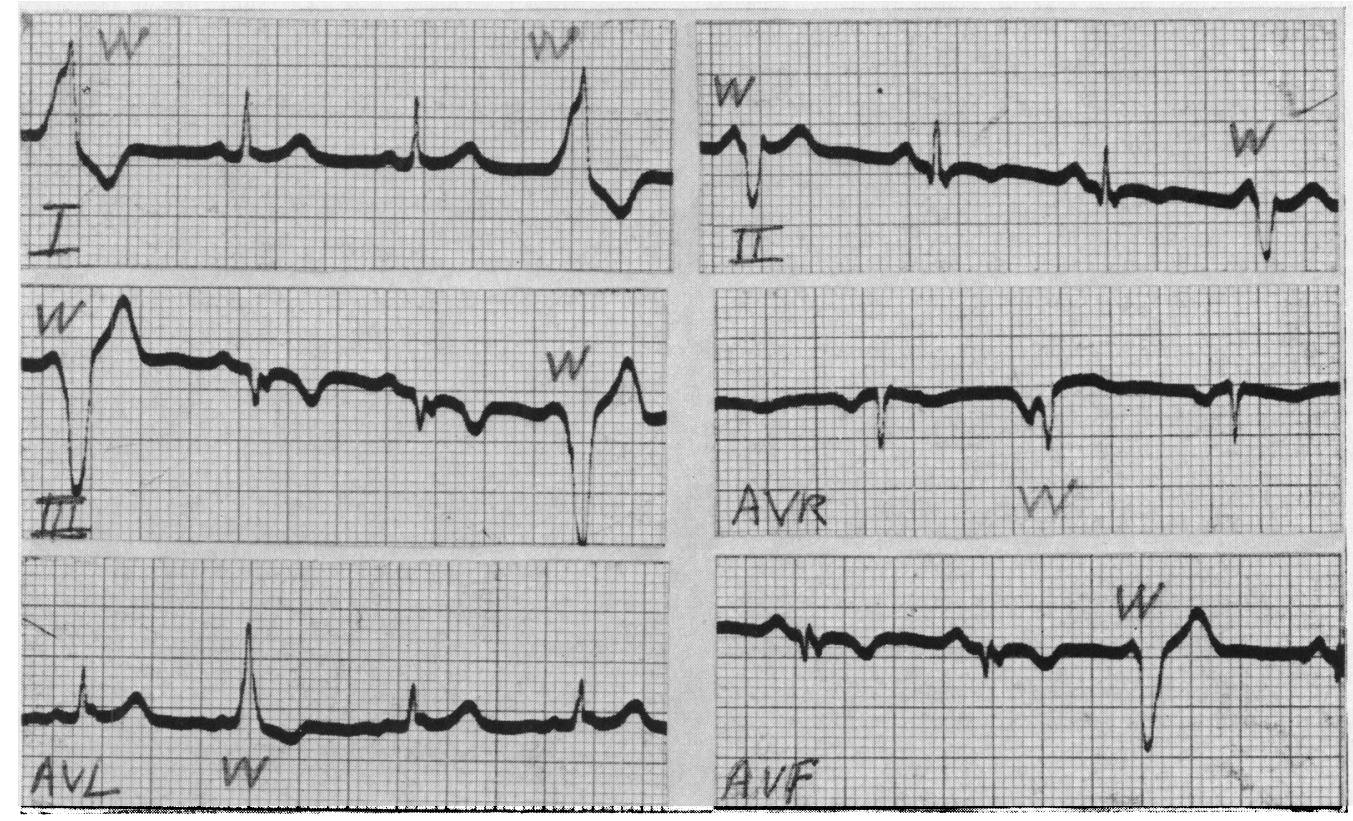

FIG. 3.-Case 3. Electrocardiogram, showing WPW complexes produced by parasystolic rhythm.

aVF as evidence of old infarction. The sinus rate was $83-88$ a minute and in the sinus beats the $P-R$ interval was 0.16 and QRS duration $0.10 \mathrm{sec}$. Aberrant complexes occur after every two sinus beats at intervals of $2 \cdot 08-2.20 \mathrm{sec}$. giving rise to a trigeminal rhythm. In leads II, III, aVL and a VF a short $\mathbf{P}-\mathbf{R}$ interval is easily recognizable in these beats. In other leads measurement of the $\mathbf{R}-\mathbf{P}$ and the $\mathbf{R}-\mathbf{R}$ intervals between the sinus beat and the following aberrant complex reveals that the QRS is superimposed upon the initial $\mathbf{P}$ deflection, thus showing that the aberrant complexes are in fact WPW beats. In the WPW beats in this case, the P-R interval varies from 0.07 to 0.14 and the QRS 
duration from 0.10 to $0.16 \mathrm{sec}$. The coupling of the QRS complex of these beats to the precedings sinus beat varied greatly.

Comment. A long tracing obtained in this patient showed that, as in the preceding two cases, the aberrant complexes were ventricular fusion beats resulting from ectopic impulse formation in a parasystolic centre.

Case 4. A 30-year-old woman was admitted with rheumatic mitral stenosis and congestive failure. The heart was considerably enlarged, the blood pressure was $95 / 75$, and the electrocardiogram showed sinus rhythm with a pattern of right ventricular strain. She was given nine tablets of digoxin in the next three days, and mercurial diuretics. Four days later there were premature beats and digoxin was stopped. Nine days afterwards a bigeminal rhythm with short runs of tachycardia was noted.

The electrocardiogram (Fig. 4) showed a bigeminal rhythm with alternate WPW beats. The P

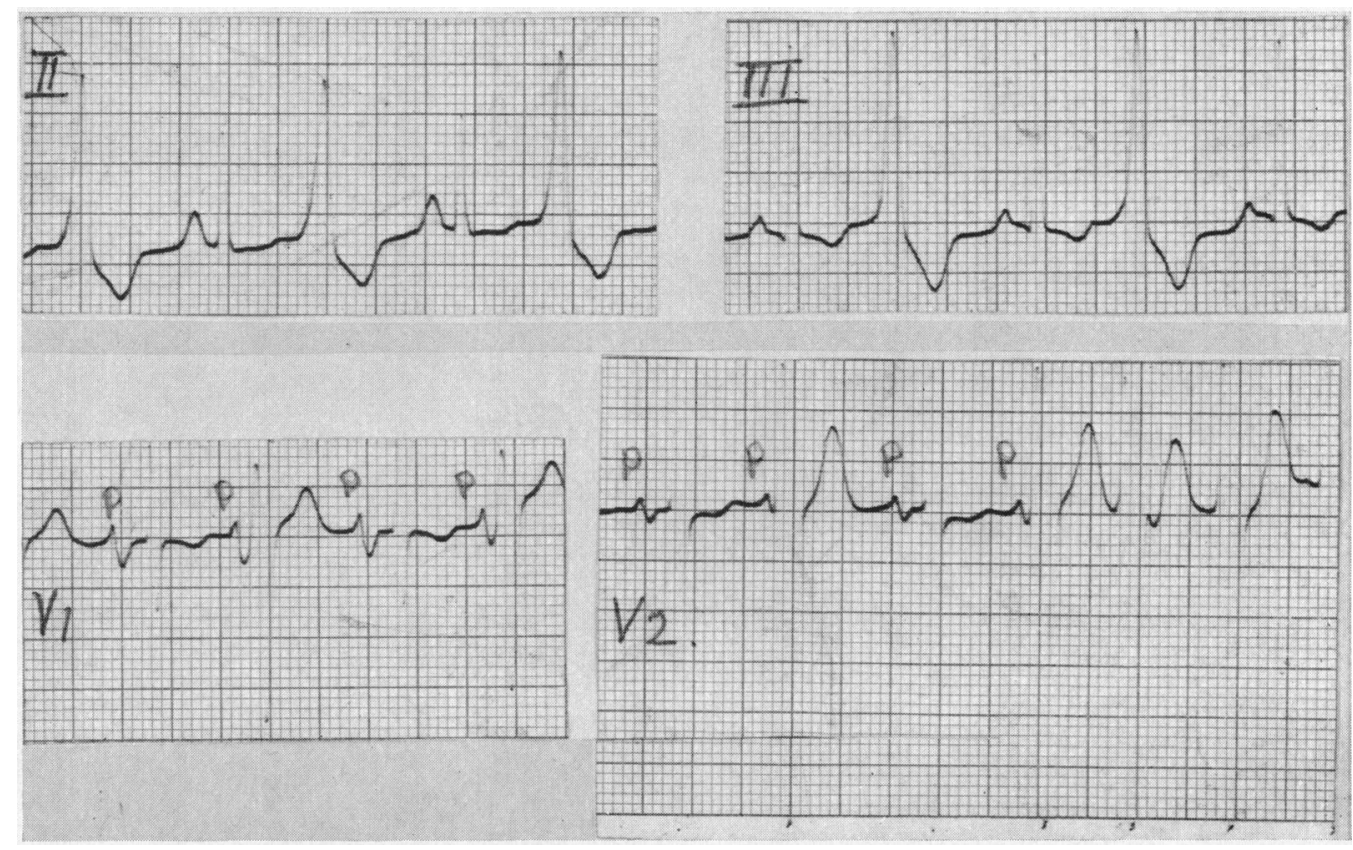

FIG. 4.-Case 4. Electrocardiogram, showing WPW syndrome with paroxysms of auricular tachycardia.

waves and the short $\mathrm{P}-\mathrm{R}$ interval were not recognizable in the limb leads but were revealed in the præcordial leads, showing that in the former the earlier part of the QRS was formed by the $\mathrm{P}$ waves. In sinus beats the P-R interval was $0 \cdot 16$ and QRS duration $0.07 \mathrm{sec}$. while in WPW beats they were 0.07 and $0.13 \mathrm{sec}$. respectively. Lead V2 showed a paroxysm of tachycardia with a rate of $144 \mathrm{a}$ minute, beginning with a WPW beat and with aberrant QRS similar to WPW beats in this lead, which terminated in V3. Ventricular premature complexes were seen in lead V4.

Comment. The paroxysm of tachycardia in this case appeared to be supra-ventricular in origin as it started with a WPW beat and its QRS complexes were similar to those of the WPW beats in the same lead. This, as well as the absence of variation of the P-R interval and of the QRS duration and contour, suggested that the WPW beats here resulted from an anomaly of impulse conduction and not of impulse formation as was seen in the first three cases. Fusion beats, however, cannot be ruled out, because of the presence of ventricular premature complexes in the same record and in preceding records, and of a shorter P-S duration in these beats than in the sinus beats. 


\section{Discussion}

The four cases reported here were from a total of twelve patients with WPW beats seen at this hospital within a period of eighteen months. Of these only one was an example of the classical WPW syndrome. The occurrence of the acquired type was therefore strikingly frequent.

It is generally agreed that pre-excitation of a small fraction of the ventricular musculature is responsible for beats with short $P-R$ interval and aberrant QRS complex. In the genuine WPW beats the impulse causing this pre-excitation originates in the S-A node. Beats of this type, however, occur unquestionably when the ventricle is stimulated from any ectopic ventricular focus (Borduas et al., 1955). If this stimulus occurs later in diastole, it interferes with the sinus impulse in the ventricles giving rise to fusion beats. Similarity of fusion beats caused by ectopic impulse formation and those caused by pre-excitation may be very close (Pick and Katz, 1955).

There seemed little doubt that in the first three cases the WPW beats resulted from ectopic impulse formation and were mostly fusion beats with variable $\mathrm{P}-\mathrm{R}$ interval and $\mathrm{QRS}$ duration and contour; in general the shorter the P-R interval the greater the QRS duration. Butterworth and Poindexter (1944) demonstrated this experimentally by producing varying shapes of fusion complexes by spacing the second ventricular stimulus at various time intervals in the cardiac cycle. Some of the WPW beats were, however, pure ectopic complexes (Case 2, lead I), the QRS occurring very prematurely and closely following the $P$ wave. In the first three cases the ectopic impulse originated in a parasystolic centre. In Case 1 this centre had the same rate of impulse formation as the sinus pacemaker. A similar rate of ectopic and sinus rhythm has been observed in dogs (Scherf, 1926) and in experimental parasystole (Scherf and Chick, 1951), and has been considered to be the cause of pre-excitation beats during cardiac catheterization (Scherf et al., 1952).

The QRS duration in some WPW and premature beats was $0.10 \mathrm{sec}$. or less, being the same as the sinus QRS (Cases 1, 2, 3). A nodal origin of these beats is obviously out of the question because of the presence of the sinus type of $P$ wave and the aberrant QRST, and of ventricular premature beats in the tracings. Again, a nodal type of parasystole usually occurs in subjects with normal electrocardiograms whereas the ventricular type is usually observed when the tracing is otherwise abnormal (Katz and Pick, 1956). The impulse in these beats presumably originated in the interventricular septum or in a focus equidistant from both the ventricular muscle masses.

The P-S interval in the WPW beats in the first, second, and fourth cases was shorter than that in the sinus beats in the same patient. Such instances, though observed by Kossman and Goldberg (1947) and Wolff and White (1948), have been considered rare (Prinzmetal et al., 1952). In these three cases (except Case 2, lead I) this could not be attributed to a pure ectopic septal or ventricular impulse occurring very prematurely (Prinzmetal et al., 1952) and the possibility that the ectopic impulse in some way accelerates the conduction of the sinus impulse has to be considered. The shorter P-S interval in Case 2, lead I, however, was due to a very premature septal or ventricular impulse.

The third and fourth cases show that the WPW character of the beats may be recognizable in some leads only. Borduas et al. (1955) illustrated a case in which only the direct auricular lead showed the shorter P-R interval.

The electrocardiographic findings in three of the four cases reported here illustrate the importance of ectopic impulse formation in the causation of WPW beats of acquired origin.

\section{SUMMARY}

Four cases showing electrocardiograms with short P-R interval and aberrant QRS complex of acquired origin are reported.

In three of them there seemed little doubt that the abnormal beats resulted from ectopic impulse formation in parasystolic centres. The beats were mostly fusion beats while some were pure ectopic complexes occurring very prematurely. In these three cases the QRS duration of some of the beats was $0 \cdot 10$ sec. or less, being either the same or less than the sinus QRS, suggesting their origin in the inter-ventricular septum or in a focus equidistant from both the ventricular muscle masses. In two instances the short $P-R$ interval was recognizable in some leads only. 
It is suggested that ectopic impulse formation is an important cause of WPW beats of acquired origin.

Dr. L. R. Sarin, Superintendent, S.M.S. Hospital, kindly permitted the publication of this report.

\section{REFERENCES}

Borduas, J. L., Rakita, L., Kennamer, R., and Prinzmetal, M. (1955). Circulation, 11, 69.

Butterworth, J. S., and Poindexter, C. A.'(1944). Amer. Heart J., 28, 149.

Hoffman, I., Morris, M. H., Friedfeld, L., and Gittler, D. (1956). Brit. Heart J., 18, 301.

Katz, L. N., and Pick, A. (1956). Clinical Electrocardiography, Part I. The Arrhythmias. Lea \& Febiger, Philadelphia. Kossman, C. E., and Goldberg, H. H. (1947). Amer. Heart J., 33, 308.

Pick, A., and Katz, L. N. (1955). Amer. J. Med., 19, 759.

Prinzmetal, M., Kennamer, R., Corday, E., Osborne, J. M., Fields, J., and Smith, L. A. (1952). Accelerated Conduction: The Wolf-Parkinson-White Syndrome and Related Conditions. Grune \& Stratton, New York.

Scherf, D. (1926). Z. gis. exp. Med., 51, 816. Cited by Scherf, D., and Schott, A. (1953). Extrasystoles and Allied Arrhythmias. William Heinemann, London.

-, Blumenfeld, S., and Mueller, P. (1952). Amer. Heart J., 43, 829

and Chick, F. B. (1951). Amer. Heart J., 42, 212.

Wolff, L., and White, P. D. (1948). Arch. intern. Med., 82, 446. 